\title{
Risk Factors Impacting Intra- and Postoperative Cerebrospinal Fluid Rhinorrhea on the Endoscopic Treatment of Pituitary Adenomas: Retrospective Experience From 250 Patients
}

\section{Ming Wang}

Second Xiangya Hospital

Cai Yang

Second Xiangya Hospital

\section{Yugang Jiang}

Second Xiangya Hospital

Yong Peng ( 188201058@csu.edu.cn )

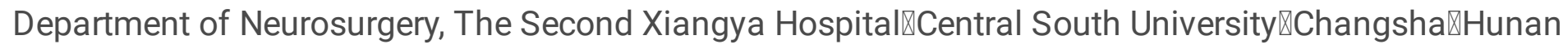
410011هChina

\section{Research}

Keywords: Pituitary Adenoma, Endoscopic Transsphenoidal Surgery, CSF Leak, Risk Factors

Posted Date: November 3rd, 2020

DOI: https://doi.org/10.21203/rs.3.rs-99694/v1

License: (9) This work is licensed under a Creative Commons Attribution 4.0 International License.

Read Full License 


\section{Abstract}

Aim: We aimed to identify the risk factors associated with intra- and postoperative cerebrospinal fluid leakage in pituitary adenomas treated by endoscopic transsphenoidal surgery.

Material and methods: A retrospective analysis of 250 pituitary adenoma cases from January 2017 to December 2019 at our hospital was conducted; all patients underwent endoscopic endonasal transsphenoidal surgeries. A univariate analysis and multivariate analysis was performed to investigate the risk factors associated with intra- and postoperative CSF rhinorrhea.

Results: Eighty(32.0\%) and nine(3.6\%) patients had intraoperative and postoperative CSF leakages, respectively. Tumor size was an independent risk factor for intraoperative CSF leakage (OR, 1.229;95\% Cl, 1.133-1.334; $P<0.001)$; intraoperative CSF leakage was an independent risk factor for postoperative CSF leakage $(\mathrm{OR}, 7.707 ; 95 \% \mathrm{Cl}, 1.336-44.455 ; \mathrm{P}=0.022)$. Chronic respiratory disease $(\mathrm{OR}, 57.500 ; 95 \% \mathrm{Cl}$, 8.031-411.682; $\mathrm{P}<0.001)$ was also an independent risk factor for postoperative CSF leakage; vascularized septal mucosal flap was a protective factor for such $(\mathrm{OR}, 0.107 ; 95 \% \mathrm{Cl}, 0.013-0.894$; $\mathrm{P}=0.039)$.

Conclusion: Intraoperative CSF leakages are more likely to occur in large pituitary adenomas; in the presence of intraoperative CSF leakages, postoperative CSF rhinorrhea is very likely to occur. Patients with chronic respiratory disease are also more likely to develop postoperative CSF leakages. However, the sellar base reconstructed using vascularized nasal septal flaps can significant decrease the risk for such. Knosp grade, degree of tumor resection, postoperative lumbar subarachnoid drain use did not seem to have effect on the postoperative CSF rhinorrhea.

\section{Introduction}

Pituitary adenomas account for $15 \%$ of all intracranial tumors. ${ }^{1}$ Endoscopic endonasal transsphenoidal surgery (EETS) has become the standard surgical treatment for pituitary adenomas, it is a reasonably safe procedure with low morbidity, particularly in experienced hands. ${ }^{2-4}$ However, postoperative cerebrospinal fluid (CSF) leakage is a major life-threatening complication following EETS, ${ }^{3}$ which may lead to meningitis ${ }^{5}$ or tension pneumocephalus, ${ }^{6}$ and is associated with a prolonged hospitalization, thus, is a potentially life- threatening complication. The incidence of such complications ranges from 0.5 to $15 \%$ following EETS ${ }^{3}$. To decrease the rates of such complications, elucidating the risk factors that affect the incidence of intra- and postoperative CSF leakage will be helpful. However, risk factors that predispose to both an intraoperative and postoperative leak remain poorly defined. In the present study, we retrospectively reviewed 375 serial cases of pituitary adenomas that treated by EETS by one surgeon. Our primary aim was to identify the predictors of intra- and postoperative CSF leakages in patients who underwent endoscopic resection of pituitary adenomas to inform patients better and educate surgeons on this potential risk. 


\section{Material And Methods}

\section{Patient population and data collection}

A retrospective review of 315 consecutive patients with pituitary adenoma from January 2017 to December 2019 was conducted. All patients were followed up for 1 to 3 years with an average follow-up period of 15.6 months. All patients underwent initial EETS by a single surgeon(Y.J.). The study was approved by the ethics committee of our hospital. Inclusion criteria were as follows: 1) a histological diagnosis of pituitary adenoma, 2) primary tumor, 3) tumor was resected by EETS completely, 4) The operation was entirely performed by one surgeon(Y.J.), 5) Records of medical data are complete. Patients without complete documentation of the these data, and patients with tumor recurrence, prior skull-base operation, and history of radiation therapy or chemotherapy were all excluded in this study.

The following data were collected retrospectively from the medical records: Demographic data, including age, race, gender and body mass index (BMI). Comorbidity, patient history, and perioperative data, including hypertension, diabetes mellitus, coronary heart disease, chronic pulmonary disease, preoperative administration of bromocriptine. Tumor characteristics, including tumor size, consistency of the adenoma, adenoma pathology type, the Grade of knosp, hemorrhage into adenoma, the extent of excision of the tumor. Other recorded features were reconstructive techniques, and the use of CSF diversion. The primary outcome was intra- and postoperative CSF leak.

\section{Surgical procedure and skull base reconstruction}

All patients underwent EETS for the resection of their tumors. After infiltrating the local nasal mucosa with adrenalin and lidocaine, we performed middle turbinate reductions bilaterally, and a VNSF was then created for those large adenomas $(\geq 10 \mathrm{~mm})$. Diamond burs were used to burr down the posterior septum, and a sphenoidotomy was enlarged using a microdebrider; the back wall of the sphenoid and the borders of the sella were visualized. The base of the sella range was located by neuronavigator, and then opened using a high-speed drill and enlarged using rongeurs. A cruciate dural incision was created; thereafter, the tumors were resected using suction and ring curettes within the pseudo capsule of the pituitary adenoma. To detect occult intraoperative CSF leakage before closure, we occasionally use the Valsalva manoeuvre.

In the absence of CSF leakage during EETS, we perform either no packing or packing only with absorbable hemostatic gauze (Surgicel) within the sella, and covered by one layer of synthetic dura, finally laid over the surface with fibrin glue or VNSF(for large adenomas). If there is evidence of minor intraoperative CSF leakage, we utilize a fat graft packing of the sella, and perform careful reconstruction of the floor of the sella with one layer of synthetic dura + VNSF or a free graft harvested from the nasal mucosa (for microadenomas ), the surface of above three repair materials usually fixed with fibrin glue. In cases with major CSF leakage, same as minor CSF leakage repair with the addition of a lumbar CSF diversion was used immediately for 5-7 days. The sella was supported by a foley balloon catheter (1214 French) for $5-7$ days.

\section{Diagnosis and management of cerebrospinal fluid leakage}


The diagnosis of a CSF leak was made as follows: (I) intra-operative CSF leak diagnosis, (1) intrasellar and (or) parasellar outflow of clear fluid, and (2) valsalva maneuver was performed when necessary; (II) post-operative CSF leak diagnosis, (1) clinical nasal outflow and positive glucose outflow, and (2) nasal endoscopic examination was performed when necessary. Postoperatively, patients with minor and intermittent CSF leakage were treated with bed rest (a posture that head is raised 30 degrees), prophylactic antibiotics, and limited activity,while, patients with major and persistent CSF leakage were treated with CSF diversion in a way of lumbar drains. A lumbar drains system would also performed for patients who failed in bed rest treatment for 7 days. All patients that failed in CSF diversion treatment $(\geq$ 7d) required reoperation via EETS.

\section{Statistical methods}

Categorical variables are presented as numbers and percentages and groups were compared using the Chi-Square and the Fisher's Exact test. Continuous variables are presented as mean and standard deviation and compared using the two-sided unpaired t-test. Factors predictive for CSF leakage in the univariate analysis $(p<0.05)$ were entered into a step-wise binary logistic regression model to identify independent factors for intra- and postoperative CSF leakage. Statistical analysis was performed using SPSS version 22.0 (IBM Corporation, Armonk, NY). A p-value < 0.05 was considered as statistically significant.

\section{Results}

\section{Patient characteristics}

Among 315 consecutive patients diagnosed with pituitary adenomas, a total of 250 patients met the inclusion criteria and included in this study from January 2017 to December 2019 at our institution. The average age of the patients was $44.1 \pm 12$.3 years. The mean hospitalization time was 8.4 days. The pathology included 187 (74.8\%) nonfunctioning adenomas, 40 (16.0\%) GH-secreting pituitary adenomas, 3 (1.2\%) PRL-secreting pituitary adenomas, 20(8.0\%) ACTH-secreting pituitary adenomas. There were 30(12.0区) case of microadenomas, 205 (82.0П) cases of macroadenomas and 15 (6.0ロ) cases of giant adenomas.

\section{Intra- and postoperative CSF leakages}

Intraoperative CSF leaks were observed during surgery in 80 patients (32.0\%), and postoperative CSF leaks occurred in 9 patients (3.6\%), respectively. Of the 80 cases with intra-operative leaks, the number of minor and major CSF leaks was 61, and 19, respectively. Postoperative CSF leaks occurred in 9 patients (3.6\%), including 7 patients with intraoperative CSF leaks and 2 patients without a recognized intraoperative CSF leak. Among 9 cases with postoperative CSF rhinorrhea, 6 cases were initially treated with 5-7 days of passive lumbar drainage, including bed rest, prophylactic antibiotics, and limited activity, whereas another 3 patients required surgical repair through a trans-sphenoidal approach. All those nine patients had resolution of their CSF leaks finally, no failures. Four patient with postoperative 
CSF leak was complicated with meningitis 2-7 days after EETS. Those patient underwent meropenem + vancomycin treatment for 14 days and was discharged from hospital without problems.

\section{Univariate analysis}

In the univariate analysis, there were three factors associated with an increased intraoperative CSF leakage rate (Table 1): (1) BMI $(P=0.013)$, (2) tumor size $(P<0.001),(3)$ consistency of the adenoma $(P=$ 0.032). Similarly, predictors of postoperative CSF leaks on univariate analysis were: (1) chronic respiratory disease (CRD) $(P<0.001)$, (2) degree of tumor resection $(P=0.011)$, and $(3)$ intraoperative CSF leakage $(P=0.021)$; only one factor was associated with a decreased postoperative CSF leakage rate: sella reconstructed by abdominal fascial graft + synthetic dura + VNSF $(P<0.001)$.

Table 1. Univariate analysis of impact of clinical characteristics associated with intraoperative CSF leak 


\begin{tabular}{|c|c|c|c|}
\hline Variable & No intraop leak(n=170) & Intraop leak(n=80) & $P$ value \\
\hline \multicolumn{4}{|l|}{ Gender } \\
\hline Female & $82(48.2 \%)$ & $48(60.0 \%)$ & \multirow[t]{2}{*}{0.219} \\
\hline Male & $88(51.8 \%)$ & $32(40.0 \%)$ & \\
\hline Age『years) & $44.15 \pm 14.52$ & $44.13 \pm 15.85$ & 0.992 \\
\hline \multicolumn{4}{|l|}{$\mathrm{BMI} \otimes \mathrm{kg} / \mathrm{m}^{2} \square$} \\
\hline$\bigotimes 18.5$ & $24(14.1 \%)$ & $20(25.0 \%)$ & \multirow[t]{4}{*}{0.013} \\
\hline $18.5-23.9$ & $88(51.8 \%)$ & $50(62.5 \%)$ & \\
\hline $24-27.9$ & $44(25.9 \%)$ & $6(7.5 \%)$ & \\
\hline$\geq 28.0$ & $14(8.2 \%)$ & $4(5.0 \%)$ & \\
\hline \multicolumn{4}{|l|}{ Hypertension } \\
\hline No & 144(84.7\%) & $60(75.0 \%)$ & \multirow[t]{2}{*}{0.191} \\
\hline Yes & $26(15.3 \%)$ & $20(25.0 \%)$ & \\
\hline \multicolumn{4}{|l|}{ Diabetes } \\
\hline No & 154(90.6\%) & 72(90.0\%) & \multirow[t]{2}{*}{1.000} \\
\hline Yes & $16(9.4 \%)$ & $8(10.0 \%)$ & \\
\hline \multicolumn{4}{|l|}{ CRD } \\
\hline No & $162(95.3 \%)$ & $72(95.0 \%)$ & \multirow[t]{2}{*}{1.000} \\
\hline Yes & $8(4.7 \%)$ & $4(5.0 \%)$ & \\
\hline \multicolumn{4}{|c|}{ Coronary heart disease } \\
\hline No & $154(90.6 \%)$ & 76(95.0\%) & \multirow[t]{2}{*}{0.621} \\
\hline Yes & $16(9.4 \%)$ & $4(5.0 \%)$ & \\
\hline \multicolumn{4}{|l|}{ Knosp Grade } \\
\hline 0 & $28(16.5 \%)$ & $16(20.0 \%)$ & \multirow[t]{3}{*}{0.641} \\
\hline $1-2$ & $106(62.4 \%)$ & $40(50.0 \%)$ & \\
\hline $3-4$ & $36(21.2 \%)$ & $24(30.0 \%)$ & \\
\hline Tumor size & $16.84 \pm 6.16$ & $26.20 \pm 7.83$ & $<0.001$ \\
\hline
\end{tabular}


Consistency of the adenoma

0.032

Tenacious

$50(29.4 \%)$

$57(71.3 \%)$

Soft

$120(70.6 \%)$

$23(28.7 \%)$

Degree of tumor resection

\begin{tabular}{|c|c|c|c|}
\hline GTR & 152(89ه) & 66(83囚) & 0.248 \\
\hline STR & 14(8.2】) & 12(15邓) & \\
\hline PR & $4(2.8 \rrbracket)$ & 2(2区) & \\
\hline \multicolumn{4}{|c|}{ Pathology } \\
\hline $\mathrm{NF}$ & $124(72.9 \%)$ & 63(78.8\%) & 0.972 \\
\hline ACTH & $16(9.4 \%)$ & $4(5.0 \%)$ & \\
\hline $\mathrm{GH}$ & $28(16.5 \%)$ & $12(15 \%)$ & \\
\hline PRL & $2(1.2 \%)$ & $1(1.2 \%)$ & \\
\hline
\end{tabular}

BMI: body mass index CRD: chronic pulmonary disease CSF囚cerebrospinal fluid

\section{Multivariate analysis}

The multivariate analysis was performed using variables significantly correlated with intraoperative CSF leakage. However, in the multivariate analysis (Table 2), only the tumor size $(P<0.001 ; 0 R, 1.229)$ was independently associated with an increased intraoperative CSF leakage rate. Similarly, the multivariate analysis was performed using variables significantly correlated with postoperative CSF leakage (Table 4) and indicated that $C R D(P<0.001 ; O R, 57.500)$ and intraoperative CSF leakage $(P=0.022 ; 0 R, 7.707)$ were the independent risk factors for postoperative CSF leakage; further, the use of VNSF + abdominal fat $(P=$ 0.039; OR, 0.107) was an independent protective factor for postoperative CSF leakage.

Table 2. Multivariate analysis of impact of clinical characteristics upon intraoperative CSF leak

\begin{tabular}{|clcr|}
\hline Variable & OR & $95 \llbracket \mathrm{Cl}$ for OR & P value \\
\hline Tumor size & 1.229 & $1.133-1.334$ & $<0.001$ \\
\hline
\end{tabular}




\begin{tabular}{|c|c|c|c|}
\hline Variable & No postop leak $(n=241)$ & postop leak $(n=9)$ & $P$ value \\
\hline \multicolumn{4}{|l|}{ Gender } \\
\hline Female & $129(53.5 \%)$ & $5(55.6 \%)$ & \multirow[t]{2}{*}{1.000} \\
\hline Male & $112(46.5 \%)$ & $4(44.4 \%)$ & \\
\hline Age(years) & $44.07 \pm 14.67$ & $45.25 \pm 18.99$ & 0.829 \\
\hline \multicolumn{4}{|l|}{$\mathrm{BMI}\left(\mathrm{kg} / \mathrm{m}^{2}\right)$} \\
\hline$\bigotimes 18.5$ & $40(16.6 \%)$ & $2(22.2 \%)$ & \multirow[t]{4}{*}{0.462} \\
\hline $18.5-23.9$ & $141(58.5 \%)$ & $2(22.2 \%)$ & \\
\hline $24-27.9$ & $44(18.3 \%)$ & $4(44.5 \%)$ & \\
\hline$\geq 28.0$ & $16(6.6 \%)$ & $1(11.1 \%)$ & \\
\hline \multicolumn{4}{|c|}{ Hypertension } \\
\hline No & 192(79.7\%) & $6(66.7 \%)$ & \multirow[t]{2}{*}{0.979} \\
\hline Yes & $49(20.3 \%)$ & $3(33.3 \%)$ & \\
\hline \multicolumn{4}{|l|}{ Diabetes } \\
\hline No & $212(88.0 \%)$ & $7(77.8 \%)$ & \multirow[t]{2}{*}{0.565} \\
\hline Yes & $29(12.0 \%)$ & $2(22.2 \%)$ & \\
\hline \multicolumn{4}{|l|}{ CRD } \\
\hline No & $230(95.4 \%)$ & $5(55.6 \%)$ & \multirow[t]{2}{*}{$<0.001$} \\
\hline Yes & $11(4.6 \%)$ & $4(44.4 \%)$ & \\
\hline \multicolumn{4}{|c|}{ Coronary heart disease } \\
\hline No & $216(89.6 \%)$ & $7(77.8 \%)$ & \multirow[t]{2}{*}{0.497} \\
\hline Yes & $25(10.4 \%)$ & $2(22.2 \%)$ & \\
\hline Tumor size & $19.56 \pm 7.82$ & $23.75 \pm 10.35$ & 0.154 \\
\hline \multicolumn{4}{|l|}{ Pathology } \\
\hline NF & $181(75.1 \%)$ & $6(66.7 \%)$ & \multirow[t]{4}{*}{0.383} \\
\hline ACTH & $19(7.9 \%)$ & $1(11.1 \%)$ & \\
\hline $\mathrm{GH}$ & $38(15.8 \%)$ & $2(22.2 \%)$ & \\
\hline PRL & $3(1.2 \%)$ & $0(0.00 \%)$ & \\
\hline
\end{tabular}




\begin{tabular}{|c|c|c|c|}
\hline Tenacious & $119(49.4 \%)$ & $5(55.6 \%)$ & \multirow[t]{2}{*}{0.451} \\
\hline Soft & $122(50.6 \%)$ & $4(44.4 \%)$ & \\
\hline \multicolumn{3}{|l|}{ Knosp Grade } & \multirow[t]{4}{*}{0.864} \\
\hline 0 & 42 & 1 & \\
\hline $1-2$ & 145 & 5 & \\
\hline $3-4$ & 54 & 3 & \\
\hline \multicolumn{3}{|l|}{ Degree of tumor resection } & \multirow[t]{4}{*}{0.011} \\
\hline GTR & 208 & 6 & \\
\hline STR & 27 & 3 & \\
\hline PTR & 6 & 0 & \\
\hline \multicolumn{3}{|l|}{ Intraoperative CSF leak } & \multirow[t]{3}{*}{0.021} \\
\hline No & $173(71.8 \%)$ & $2(22.2 \%)$ & \\
\hline Yes & $68(28.2 \%)$ & $7(77.8 \%)$ & \\
\hline \multicolumn{3}{|l|}{ Sella reconstruction methods } & \multirow[t]{4}{*}{$<0.001$} \\
\hline synthetic dura+biological glue & 166(68.9区) & 3(33.3区) & \\
\hline abdominal fat+ dura+free graft & $28(11.6 \%)$ & $6(66.7 \%)$ & \\
\hline abdominal fat+ dure+VNSF & 47 (19.5\%) & $0(0 \%)$ & \\
\hline \multicolumn{3}{|l|}{ lumbar subarachnoid drain } & \multirow[t]{3}{*}{0.286} \\
\hline No & $226(93.8 \%)$ & $7(77.8 \%)$ & \\
\hline Yes & $15(6.2 \%)$ & $2(22.2 \%)$ & \\
\hline
\end{tabular}

BMI: body mass index CRD: chronic pulmonary disease VNSF囚vascularized nasal septal flap CSF》 cerebrospinal fluid NF: no functioning GTR囚gross total resection STR: sub-total resection PR: partial resection

Table 4. Multivariate analysis of impact of clinical characteristics upon postoperative CSF leak 


\begin{tabular}{|llll|}
\hline Variable & OR & $95 \rrbracket C l$ for OR & P value \\
\hline CRD & 57.500 & $8.031-411.682$ & $<0.001$ \\
\hline Intraoperative CSF leak & 7.707 & $1.336-44.455$ & 0.022 \\
\hline VNSF+ abdominal fat graft & 0.107 & $0.013-0.894$ & 0.039 \\
\hline
\end{tabular}

$\mathrm{CRD} \llbracket$ chronic pulmonary disease VNSF『vascularized nasal septal flap

\section{Discussion}

EETS continues to improve owing to recent advances in equipment, hemostatic reagents, and closure techniques; the incidence of CSF leakage has been reduced to a range from 0.5 to $12 \%$ following EETS. ${ }^{1,7-9}$ However, there are still some factors unrelated to surgical skills that could impact the rates of intra- and postoperative CSF leakage; those factors have been poorly defined, and our data suggest that certain factors can predict a greater likelihood of CSF leakages both in the intra- and postoperative periods of EETS.

In studies of CSF leakage in pituitary adenomas after transnasal surgery, most of the researchers found that CSF leakage occurred in most patients with an intraoperative CSF leakage, $3,4,10$ thus, intraoperative CSF leakage seems to be an important risk factor for postoperative CSF leakage. Similarly, this conclusion was also confirmed in our study. Nine patients had a postoperative CSF leakage, and seven of them had an intraoperative CSF leakage; the final multivariate regression analysis showed intraoperative CSF leakage as an independent risk factor for postoperative CSF leakage (OR, 7.707; $P=0.022)$.

Based on the results above, we can see that it is important to prevent intraoperative CSF leakage to reduce the rate of postoperative CSF leakage; understanding the risk factors of intraoperative CSF leakage is beneficial in its management and prevention of postoperative CSF leakage. It is obvious that all the factors that can induce diaphragma sellae rupture can lead to a CSF leakage; thus, the factors impacting the rupture of the diaphragm sellae can also lead to intraoperative CSF leakages. In our reports, we observed the significant difference in the tumor size between those who had an intraoperative CSF rhinorrhea and those who did not $(16.84 \pm 6.16$ vs $26.20 \pm 7.83 ; \mathrm{P}<0.001)$. Zhou et al. ${ }^{4}$ also reported a high incidence of intraoperative CSF leakage following a large size pituitary adenoma resection; the final multi-factor regression analysis demonstrated that it was an independent risk factor for intraoperative CSF rhinorrhea. The mechanism of the tumor size being a risk factor of CSF leakage in surgery may be due to suprasellar extension in large size tumor,which can leading to a rather thin diaphragm sellae. Therefore, we think a gentle manipulation is necessary for large pituitary adenomas to avoid the rapture of a rather thin diaphragm sellae in surgery. At the same time, we can also remove the tumor in the following order: rear, two sides, and front to avoid dropping the diaphragma sellae too early and too fast, which may lead to its rupture and consequently CSF leakage. 
Our results revealed that CRD had increased the risk of postoperative CSF leakage $(O R, 57.5 ; \mathrm{P}<0.01)$. To our knowledge, this has never been reported in the literature until now. This result may be related to the increased intracranial pressure during the acute onset of CRD. The increased intrathoracic pressure leading to a decreased blood flow of the jugular vein resulting in an increased intracranial pressure may cause herniation of the repaired material from the sellar base and CSF leakage. Two other studies ${ }^{11,12}$ had proven the mechanism of an increased intracranial pressure playing an important role in the occurrence of postoperative CSF leakage or a spontaneous CSF leakage. Hanba et al. ${ }^{12}$ discovered that patients with asthma are more likely to have CSF leakage than patients without asthma after transnasal surgery; further, the rate of postoperative CSF leakage in these two groups was $4.7 \%$ and $2.7 \%$, respectively. Fleischman et al. ${ }^{11}$ found that patients with obstructive sleep apnea are more likely to develop a spontaneous CSF leakage.

Previous studies 3,13 have already reported that BMI was a risk factor for postoperative CSF leakage following EETS, however, incidence of CSF leakage did not correlate with BMI in our series. Dlouhy et al. ${ }^{13}$ and Karnezis et al. ${ }^{3}$ both indicated that BMI was a risk factor for postoperative CSF leakage. However, the average BMI of the CSF leakage group compared with that of the non-CSF leakage group in these two studies was $33.1: 30.3 \mathrm{~kg} / \mathrm{m}^{2}$ and $39.2: 32.9 \mathrm{~kg} / \mathrm{m}^{2}$, respectively; both of their patients' average BMI was greater than $30 \mathrm{~kg} / \mathrm{m}^{2}$. In our study, the average BMI was $\sim 21.80: 21.66 \mathrm{~kg} / \mathrm{m}^{2}$, which was lower than those in the previous studies. We think it is possible that the average BMI in our patients was not elevated enough to lead to a spontaneous increase in the intracranial pressure, which can result in postoperative CSF rhinorrhea.

Some studies have suggested that a VNFP can reduce the incidence of postoperative CSF leakage to less than $6 \% .{ }^{14-16}$ Currently, using vascularized mucosal flaps has become a recognized method for sellar base reconstruction. Obviously, the incidence of postoperative CSF leakage in our patients significantly reduced by the use of VNFP and abdominal fascial graft. The blood supply of the VNFPs was mainly derived from the septal artery, which is rich in blood flow; thus, the survival rate was higher than those in any other non-vascular mucosal flaps. ${ }^{14}$ El-sayed et al. ${ }^{14}$ also pointed out that the atrophy of the mucous with a VNFP was smaller than that with a non-vascular mucosa flap, which was not enough to detach the mucosal flap from the sellar base.

Whether the use of lumbar subarachnoid drains reduces the rates of postoperative CSF rhinorrhea remains controversial. ${ }^{17,18}$ Some researchers noted that the use of intraoperative lumbar subarachnoid drain did not significantly reduce the postoperative CSF leakage rate. ${ }^{19,18}$ However, Stokken et al. ${ }^{20}$ indicated that in patients with a high-flow intraoperative CSF leakage, the use of a lumbar subarachnoid drain can immediately reduce the risk for postoperative CSF leakage. Conversely, our study found that the use of such did not significantly reduce the risk of postoperative CSF leakage. Using a lumbar subarachnoid drain can also easily lead to intracranial infection ${ }^{18}$ and prolonged hospitalization; ${ }^{19}$ thus, we think careful consideration in using a lumbar subarachnoid drain intraoperatively to prevent postoperative CSF leakage is necessary. 


\section{Conclusion}

In the nasal transsphenoidal endoscopic resection of pituitary adenomas, patients with a large tumor should be strictly monitored for intraoperative CSF leakage; in the presence of intraoperative CSF leakage, sellar base defects should be more carefully repaired to avoid postoperative CSF leakage. The sella constructed by abdnominal fat + VNFP can help lower the rate of postoperative CSF leakage; as such, a VNSF should be created ahead of time for these patients. For patients comorbidity with CRD, the postoperative management must be more cautiously provided, and respiratory management are necessary to reduce inflammatory reactions in the postoperative period. These measures can effectively reduce the risk of postoperative CSF leakage.

\section{Declarations}

\section{Acknowledgements}

No

\section{Conflicts of Interest}

The authors declare that they have no financial or other conflicts of interest in relation to this research and its publication.

\section{Authors' contributions}

YP conceived and designed the study. MW and YC performed the statistical analyses. YJ, MW, and YC contributed in collecting and interpreting data as well as in drafting and critically revising the manuscript. All authors approved the final version of the manuscript and are accountable for the accuracy and integrity in all aspects of the study.

\section{Funding}

None.

\section{Availability of data and materials}

The data that support the findings of this study are available on request from the corresponding author. The data are not publicly available due to privacy or ethical restrictions.

\section{Ethics approval and consent to participate}

This study was approved by the Institutional Review Board of Second Xiangya Hospital of Central South University.

\section{Consent for publication}


This study was obtained informed consent from all patients.

\section{References}

1. LoyoVarela M, HerradaPineda T, RevillaPacheco F, et al. Pituitary tumor surgery: review of 3004 cases. World neurosurgery 2013; 79, 331-6.

2. Dehdashti AR, Ganna A, Karabatsou K, et al. Pure endoscopic endonasal approach for pituitary adenomas: early surgical results in 200 patients and comparison with previous microsurgical series. Neurosurgery 2008; 62: 1006-1015.

3. Karnezis TT, Baker AB, Soler ZM, et al. Factors impacting cerebrospinal fluid leak rates in endoscopic sellar surgery. Int Forum Allergy Rhinol 2016; 6: 1117-1125.

4. Zhou Q, Yang Z, Wang X, et al. Risk factors and management of intraoperative cerebrospinal fluid leaks in endoscopic treatment of pituitary adenoma: analysis of 492 patients. World Neurosurgery 2017; 101:390-395.

5. Black PM, Zervas NT, Candia GL. Incidence and management of complications of transsphenoidal operation for pituitary adenomas. Neurosurgery 1987; 20: 920-924.

6. Sawka AM, Aniszewski JP, Jr YW, et al. Tension pneumocranium, a rare complication of transsphenoidal pituitary surgery: Mayo Clinic experience 1976-1998. J Clin Endocrinol Metab 1999; 84: 4731-4734.

7. Paluzzi A, Fernandez-Miranda JC, Tonya Stefko S, et al. Endoscopic endonasal approach for pituitary adenomas: a series of 555 patients. Pituitary 2014; 17: 307-319.

8. Wang F, Zhou T, Wei S, et al. Endoscopic endonasal transsphenoidal surgery of 1,166 pituitary adenomas. Surg Endosc 2015; 29: 1270-1280.

9. Shiley SG, Limonadi F, Delashaw JB, et al. Incidence, etiology, and management of cerebrospinal fluid leaks following trans-sphenoidal surgery. Laryngoscope 2003; 113: 1283-1288.

10. Magro E, Graillon T, Lassave J, et al. Complications related to the endoscopic endonasal transsphenoidal approach for nonfunctioning pituitary macroadenomas in 300 consecutive patients. World Neurosurg 2016; 89: 442-453.

11. Fleischman GM, Ambrose EC, Rawal RB, et al. Obstructive sleep apnea in patients undergoing endoscopic surgical repair of cerebrospinal fluid rhinorrhea. Laryngoscope 2014; 124: 2645-2550.

12. Hanba C, Svider PF, Jacob JT, et al. Lower airway disease and pituitary surgery: is there an association with postoperative cerebrospinal fluid leak? Laryngoscope 2017; 127: 1543-1550.

13. Dlouhy BJ, Madhavan K, Clinger JD, et al. Elevated body mass index and risk of postoperative CSF leak following transsphenoidal surgery. J Neurosurg 2012; 116: 1311-1317.

14. El-Sayed IH, Roediger FC, Goldberg AN, et al. Endoscopic reconstruction of skull base defects with the nasal septal flap. Skull Base 2008; 18: 385-394.

15. Hadad G, Bassagasteguy L, Carrau R L, et al. A novel reconstructive technique after endoscopic expanded endonasal approaches: vascular pedicle nasoseptal flap. Laryngoscope 2006; 116: 1882- 
1886.

16. Horiguchi K, Murai H, Hasegawa Y, et al. Endoscopic endonasal skull base reconstruction using a nasal septal flap: surgical results and comparison with previous reconstructions. Neurosurg Rev 2010; 33: 235-241.

17. Casiano RR, Jassir D. Endoscopic cerebrospinal fluid rhinorrhea repair: is a lumbar drain necessary? Otolaryngol Head Neck Surg 1999; 121: 745-750.

18. Ransom ER, Palmer JN, Kennedy DW, et al. Assessing risk/benefit of lumbar drain use for endoscopic skull-base surgery. Int Forum Allergy Rhinol 2011; 1: 173-177.

19. Ahmed OH, Marcus S, Tauber JR, et al. Efficacy of perioperative lumbar drainage following endonasal endoscopic cerebrospinal fluid leak repair: a meta-analysis. Otolaryngol Head Neck Surg 2017; 156:52-60.

20. Stokken J, Recinos PF, Woodard T, et al. The utility of lumbar drains in modern endoscopic skull base surgery. Curr Opin Otolaryngol Head Neck Surg 2015; 23: 78-82. 